\title{
Pengaruh Kinerja Keuangan Terhadap Return Saham Perusahaan Food And Beverage Tahun 2013-2018
}

\author{
Yohanes dan Maswar \\ Program Studi Manajemen, Fakultas Ekonomi dan Bisnis \\ Universitas Tarumanagara, Jakarta \\ Email: ysuriadi@gmail.com
}

\begin{abstract}
This study aims to empirically analyze the effect of firm's financial performance based on financial ratios that is Current Ratio, Debt Equity Ratio, Total Asset Turnover, Return on Equity, and Earnings per Share on stock return of food and beverage companies listed in Indonesia Stock Exchange between 2013-2018. This study adopted the panel data regression method using Eviews 10 as its tool. The findings of this research concluded that Current Ratio, Debt Equity Ratio, and Return on Equity significantly affected the stock return of food and beverage companies between 2013-2018. This study findings concluded that investors can use those three ratios to predict future stock returns, especially food and beverage companies.
\end{abstract}

Keywords: stock return, financial ratio, stock, food and beverage stock, publication date

Abstrak: Penelitian ini ditujukan untuk menganalisis secara empiris pengaruh kinerja keuangan perusahaan, diukur menggunakan rasio keuangan yaitu Rasio Lancar, Rasio Utang Modal, Rasio Penjualan terhadap Total Aset, Rasio Pengembalian terhadap Modal, dan Rasio Penerimaan per Lembar Saham terhadap tingkat pengembalian saham perusahaan makanan dan minuman yang terdaftar di Bursa Efek Indonesia tahun 20132018. Penelitian ini menggunakan regresi data panel dengan aplikasi Eviews 10. Penelitian ini menyimpulkan bahwa Rasio Lancar, Rasio Utang Modal, dan Rasio Pengembalian terhadap Modal berpengaruh secara signifikan terhadap tingkat pengembalian saham perusahaan makanan dan minuman. Hasil dari penelitian ini menyimpulkan bahwa para investor dapat menggunakan tiga rasio tersebut untuk memprediksi tingkat pengembalian saham di masa depan, khususnya perusahaan makanan dan minuman.

Kata kunci: tingkat pengembalian saham, rasio keuangan, saham, saham makanan dan minuman, tanggal publikasi.

\section{LATAR BELAKANG}

Saham adalah salah satu produk sekuritas dari pasar modal. Saham itu sendiri merupakan bagian kepemilikan dari suatu perusahaan. Saham terdiri atas dua macam, yaitu Preferred Stock (Saham Preferren) dan Common Stock (Saham Biasa). Saham umumnya dijual dalam bentuk Common Stock yang berarti saham biasa, karena Preferred Stock atau yang berarti saham preferen biasanya tidak dijual umum, hanya dimiliki petinggi-petinggi perusahaan saja.

Setiap berinvestasi, yang diharapkan adalah return. Return menurut Hartono (2017) adalah hasil yang diperoleh dari investasi. Return total merupakan return keseluruhan dari suatu investasi dalam suatu periode tertentu. Return total sering disebut dengan return saja. Return total terdiri dari capital gain (loss) dan yield. Capital Gain adalah keuntungan 
berupa kenaikkan harga saham, sebaliknya Capital Loss merupakan kerugian berupa penurunan harga saham. Yield merupakan keuntungan dari pembagian dividend. Dividend adalah pembagian keuntungan perusahaan kepada pemilik saham.

"Financial ratios provide a quick and relatively simple means of assessing the financial health of a business" (McLaney \& Atrill, 2005). Kalimat ini menunjukkan bahwa rasio keuangan menyediakan cara penilaian kesehatan (kinerja) perusahaan yang relatif cepat dan ringkas. Jika perusahaan sehat, return akan meningkat, sebaliknya jika perusahaan tidak sehat, return bisa turun.

Rasio keuangan terbagi menjadi lima kelompok, yaitu rasio likuiditas, rasio solvabilitas (leverage), rasio aktivitas, rasio profitabilitas, dan rasio pasar. Lima rasio tersebut adalah Current Ratio, Debt Equity Ratio, Total Asset Turnover, Return on Equity, dan Earnings per Share. Masing-masing rasio mewakili satu jenis rasio. Lima rasio di atas dianggap berpengaruh pada return saham makanan dan minuman. Hal yang dicari dari penelitian ini apakah rasio-rasio tersebut berpengaruh terhadap return saham.

Penelitian ini dapat memberi manfaat bagi perusahaan dan investor. Bagi perusahaan khususnya perusahaan makanan dan minuman dapat menggunakan informasi rasio keuangan sebagai motivasi untuk meningkatkan kinerja perusahaan, agar dapat meningkatkan return saham. Agar saham tersebut semakin diminati. Bagi investor dapat menggunakan analisis rasio untuk menentukan apakah saham yang diincar layak dibeli atau tidak.

\section{KAJIAN TEORI}

Dividend Growth Theory. Ada tiga model, yaitu Zero Growth Model, Constant Growth Model, dan Supernormal Growth Model. Namun yang menjadi landasan adalah Constant Growth Model. Model ini yang paling biasa digunakan, mengasumsikan bahwa deviden tumbuh setiap tahun secara konstan. Teori di dalam ini adalah bagaimana pengaruh $\mathrm{Ks}$ terhadap harga saham. Ks tersebut angkanya tergantung risk premium dan risk-free rate. Nilai wajar saham dihitung dengan membagi deviden tahun depan dengan selisih required rate of return dengan growth (pertumbuhan). Dimana perhitungan deviden tahun depan dilakukan dengan cara menjumlahkan deviden tahun ini dengan nilai growth dikali deviden tahun ini.

$$
\begin{aligned}
& P_{0}=\frac{D_{1}}{K_{s}-g} \\
& D_{1}=D_{0}(1+g) \\
& \mathrm{D}_{1}=\text { Deviden tahun yang akan datang } \\
& \mathrm{D}_{0}=\text { Deviden tahun ini } \\
& \mathrm{g}=\text { growth (pertumbuhan) }
\end{aligned}
$$

Kinerja Keuangan. Kinerja keuangan adalah penentuan ukuran-ukuran tertentu yang dapat mengukur keberhasilan suatu perusahaan dalam menghasilkan laba (Sucipto, 2003). Menurut Widayanti dan Colline (2017), kinerja keuangan perusahaan dapat dilakukan 
dengan menganalisis laporan keuangan. Salah satu bentuk analisis laporan keuangan adalah dengan menganalisis rasio-rasio keuangan.

"This research explicates the premise that the financial ratios can predict the stock returns, and volatility in stock prices, over a period of time" (Shaikh, Kashif, dan Shaikh, 2017). Kalimat ini berarti penelitian yang dikerjakannya menunjukkan bahwa rasio keuangan dapat memprediksi return saham dan volatilitas dalam periode waktu tertentu. Karena dapat diprediksi, ini memberikan persepsi baru bagi investor. Ketertarikan investor terhadap suatu saham dapat memengaruhi return saham.

Return Saham. Return menurut Hartono (2017, h. 283) adalah sebagai berikut.

"Return merupakan hasil yang diperoleh dari investasi... Return total merupakan return keseluruhan dari suatu investasi dalam suatu periode tertentu. Return total sering disebut dengan return saja. Return total terdiri dari capital gain (loss) dan yield. “

Capital Gain adalah keuntungan berupa kenaikkan harga saham, sebaliknya Capital Loss merupakan kerugian berupa penurunan harga saham. Yield merupakan keuntungan dari pembagian dividend. Dividend adalah pembagian keuntungan perusahaan kepada pemilik saham.

Rasio Keuangan dan Hubungannya terhadap Return Saham. Menurut Munawir (2010), analisis rasio keuangan adalah berorientasi dengan masa depan, artinya bahwa dengan analisa ratio keuangan bisa digunakan sebagai alat untuk meramalkan keadaan keuangan serta hasil usaha dimasa mendatang. Al-Tamimi (2007) menyatakan "the cause of increase or decrease in demand for a particular stock is determined by the firms' fundamentals, external factors and market behavior". Pernyataan tersebut menyatakan bahwa peningkatan dan penurunan nilai saham ditentukan oleh faktor fundamental (rasio keuangan), faktor eksternal, dan perilaku pasar (rasio pasar).

Ada juga Menurut Widayanti dan Colline (2017), kinerja keuangan perusahaan dapat dilakukan dengan menganalisis laporan keuangan. Salah satu bentuk analisis laporan keuangan adalah dengan menganalisis rasio-rasio keuangan.

Rasio Likuiditas dan Hubungannya terhadap Return Saham. Rasio likuiditas adalah rasio yang menggambarkan kemampuan suatu perusahaan untuk melunasi semua kewajiban yang harus segera dipenuhi (hutang jangka pendeknya). Current ratio merupakan rasio likuiditas. Rasio ini menunjukkan perbandingan nilai kekayaan lancar (yang segera dapat dijadikan uang) dengan hutang jangka pendek (Munawir, 2007). Current ratio merupakan rasio perusahaan membayar kewajiban jangka pendek. Rumus Current Ratio menurut Kenton (2019b), Gitman dan Zutter (2012) adalah Current Asset dibagi Current Liabilities.

Current Ratio $=\frac{\text { Current Asset }}{\text { Current Liabilities }}$

Current Ratio berarti semakin baik kemampuan perusahaan untuk melunasi kewajiban jangka pendeknya. Hal ini didukung oleh penelitian oleh W dan Sujana (2014), dan penelitian dari Syaiful Dian (2016). Keduanya menyatakan bahwa Current Ratio 
berpengaruh positif dan signifikan terhadap return saham. Satu lagi penelitian oleh Setiyawan dan Pardiman (2014) menyatakan bahwa Current Ratio berpengaruh positif dan signifikan terhadap harga saham.

Rasio Solvabilitas dan Hubungannya terhadap Return Saham. Rasio solvabilitas (leverage) adalah rasio yang menunjukkan kemampuan perusahaan dalam memenuhi segala kewajibannya baik jangka pendek maupun jangka panjang apabila perusahaan dilikuidasi. Rasio solvabilitas merupakan merupakan rasio yang digunakan untuk mengukur sejauh mana aktiva perusahaan dibiayai dengan utang (Kasmir, 2013).

Debt to Equity Ratio selain digunakan untuk melihat struktur permodalan perusahaan juga bisa digunakan untuk melihat tingkat solvabilitas (penggunaan hutang) terhadap total shareholder's equity (Ang, 1997). Debt Equity Ratio merupakan rasio besarnya utang terhadap modal. Rumusnya menurut Kenton dan Hayes (2019) adalah sebagai berikut.

\section{Debt Equity Ratio $=\frac{\text { Total Liabilities }}{\text { Total Shareholders'Equity }}$}

Meningkatnya nilai Debt Equity Ratio berarti meningkatnya jumlah utang yang dimiliki oleh perusahaan. Meskipun nilai $D E R$ semakin besar, belum tentu keuntungan akan berkurang, hal ini tergantung pada besarnya biaya modal dari pendanaan yang baru. Jika biaya modal lebih besar dibanding dibanding tingkat pengembalian terhadap asset, hal ini akan mengurangi laba. Sebaliknya jika biaya modal lebih kecil dibanding nilai tingkat pengembalian terhadap asset, hal ini akan meningkatkan keuntungan.

Karena sebab di atas, maka dari itu terdapat perbedaan hasil antara beberapa penelitian yang sudah dilakukan. Seperti penelitian oleh W dan Sujana (2014) menyatakan bahwa Debt Equity Ratio berpengaruh negatif terhadap return saham food and beverage. Satu lagi penelitian oleh Permatasari dan Mukaram (2019) menyatakan Debt Equity Ratio berpengaruh secara negatif terhadap harga saham. Adapun yang memiliki hasil berbeda, dalam penelitian oleh Purwitajati dan Putra (2016) yang menyatakan Debt Equity Ratio berpengaruh positif dan signifikan terhadap return saham property.

Rasio Aktivitas dan Hubungannya terhadap Return Saham. Rasio aktivitas merupakan efektivitas perusahan dalam menggunakan aktiva yang dimiliknya atau dapat pula dikatakan rasio ini digunakan untuk mengukur tingkat efisiensi pemanfaatan sumber daya perusahan (Kasmir, 2013).

Total Asset Turnover merupakan rasio aktivitas. Asset turnover (total asset turn over) is a ratio that measures how all assets owned by a company are operated in supporting company sales (Sitanggang, 2013). Pernyataan tersebut menunjukkan bahwa Total Asset Turnover merupakan rasio yang mengukur bagaimana seluruh asset yang dimiliki menopang hasil penjualan perusahaan. Rumusnya menurut Gitman dan Zutter (2012) adalah sebagai berikut.

Total Asset Turnover $=\frac{\text { Sales }}{\text { Total Asset }}$

Jika nilainya semakin meningkat, maka akan meningkatkan persepsi bahwa hasil penjualan tinggi. Sebaliknya jika semakin menurun, aka nada persepsi bahwa penjualan lesu. Maka dari itu rasio ini berpengaruh terhadap persepsi investor. Penelitian oleh $\mathrm{W}$ dan 
Sujana (2014) menyatakan bahwa Total Asset Turnover berpengaruh positif dan signifikan terhadap return saham food and beverage. Ada juga hasil penelitian yang berbeda oleh Ikhsani (2018) yang menyatakan bahwa Total Asset Turnover tidak berpengaruh signifikan terhadap return saham.

Rasio Profitabilitas dan Hubungannya terhadap Return Saham. Rasio profitabilitas digunakan untuk mengetahui kemampuan perusahaan untuk mendapatkan laba dari pendapatan. Return on Equity merupakan rasio profitabilitas. Return On Equity (ROE) adalah kemampuan perusahaan dalam menghasilkan keuntungan dengan modal sendiri yang dimiliki, sehingga return on equity ini ada yang menyebutnya sebagai rentabilitas modal sendiri (Hadi, 2000). Rumusnya menurut Sarkar (2018) adalah sebagai berikut.

Return on Equity $=\frac{\text { Net Income }(\text { Annual })}{\text { Shareholders' } \text { Equity }^{\prime}}$

Return on Equity merupakan rasio profitabilitas. Return On Equity (ROE) adalah kemampuan perusahaan dalam menghasilkan keuntungan dengan modal sendiri yang dimiliki, sehingga return on equity ini ada yang menyebutnya sebagai rentabilitas modal sendiri (Hadi, 2000). Return on Equity mengukur jumlah proporsi laba dibanding dengan modal yang dimiliki perusahaan. Rasio ini menunjukkan bahwa laba yang semakin besar belum tentu semakin baik. Tingkat Return on Equity yang tinggi menunjukkan kemampuan perusahaan dalam menghasilkan besar laba dibanding jumlah modal tertentu bagi pemilik saham. Tentu saja ini menyebabkan tingkat return saham meningkat juga. Hal ini didukung oleh penelitian dari Setiyawan dan Pardiman (2014) yang menyatakan bahwa Return On Equity (ROE) berpengaruh positif dan signifikan terhadap Harga Saham.

Rasio Pasar dan Hubungannya terhadap Return Saham. Earnings per Share adalah rasio pasar. "Market ratios are the ones are used for investment decisions and long-term planning" (Saeidi, 2011). Ini berarti rasio pasar merupakan rasio yang digunakan untuk keputusan investasi dan perencanaan jangka panjang. Rumusnya menurut Chen (2019) adalah sebagai berikut.

\section{Net Income - \\ Earnings per Share $=\frac{\text { Preffered Dividends }}{\text { End-of-period Common }}$ \\ Shares Outstanding}

Jika Earnings per Share semakin meningkat, maka tingkat pengembalian saham juga meningkat, sebaliknya jika Earnings Per Share menurun, tingkat pengembalian juga menurun. Hal ini didukung oleh penelitian dari Widayanti dan Colline (2017) yang menyatakan bahwa Signifikan berpengaruh terhadap harga saham. Shaikh, Kashif, dan Shaikh (2017) juga menyatakan dalam penelitiannya bahwa Earnings per Share merupakan alat ukur paling signifikan terhadap harga saham. Ada juga penlitian dengan hasil yang berbeda, yaitu penelitian oleh Rahmawati (2017) yang menyatakan bahwa Earnings per Share tidak memiliki pengaruh signifikan terhadap return saham.

Berdasarkan landasan teori yang sudah dipaparkan di atas, peneliti dapat mengambil lima hipotesis mengambil Current Ratio $\left(\mathrm{X}_{1}\right)$, Debt Equity Ratio $\left(\mathrm{X}_{2}\right)$, Total Asset Turnover $\left(\mathrm{X}_{3}\right)$, Return on Equity $\left(\mathrm{X}_{4}\right)$, dan Earnings per Share $\left(\mathrm{X}_{5}\right)$ sebagai variabel 
independen. Lalu diambil Return Saham $\left(\mathrm{Y}_{1}\right)$ sebagai variabel dependen. Hipotesis penelitian ini sebagai berikut.

$\mathrm{H}_{1}$ : Current Ratio berpengaruh positif terhadap return saham Perusahaan makanan dan minuman.

$\mathrm{H}_{2}$ : Debt Equity Ratio berpengaruh negatif terhadap return saham Perusahaan makanan dan minuman.

$\mathrm{H}_{3}$ : Total Asset Turnover berpengaruh positif terhadap return saham Perusahaan makanan dan minuman.

$\mathrm{H}_{4}$ : Return on Equity berpengaruh positif terhadap return saham Perusahaan makanan dan minuman.

$\mathrm{H}_{5}$ : Earnings per Share berpengaruh positif terhadap return saham Perusahaan makanan dan minuman.

\section{METODE PENELITIAN}

Data kuantitatif diambil dari situs web BEI (Bursa Efek Indonesia), yaitu laporan keuangan Perusahaan makanan dan minuman yang akan diobservasi. Data kuantitatif adalah jenis data yang dapat diukur (measurable) atau dihitung secara langsung sebagai variabel angka atau bilangan. Data yang digunakan dalam skripsi ini adalah data sekunder. Yaitu merupakan data yang diperoleh dari pengumpul data primer dan telah diolah.

Analisis data menggunakan Regresi Data Panel yang berarti adalah gabungan antara data cross section dan data time series, dimana unit cross section yang sama diukur pada waktu yang berbeda. Maka dengan kata lain, data panel merupakan data dari beberapa individu sama yang diamati dalam kurun waktu tertentu (Hidayat, 2017c). Umumnya pendugaan parameter dalam analisis regresi dengan data cross section dilakukan menggunakan pendugaan metode kuadrat terkecil atau disebut Ordinary Least Square (OLS) (Hidayat, 2017c). Persamaan tersebut adalah sebagai berikut.

$Y=\alpha+\beta_{1} x_{1}+\beta_{2} x_{2}+\beta_{3} x_{3}+\beta_{4} x_{4}+\beta_{5} x_{5}+\varepsilon$

$\mathrm{Y}=$ Return Saham

$\alpha=$ Konstanta

$\beta_{1,2,3,4,5}=$ Koefisien regresi

$\mathrm{X}_{1}=$ Current Ratio

$\mathrm{X}_{2}=$ Debt Ratio
$\mathrm{X}_{3}=$ Total Asset Turnover

$\mathrm{X}_{4}=$ Return on Equity

$\mathrm{X}_{5}=$ Earning Per Share

$\varepsilon=$ Selisih nilai $\mathrm{Y}$ yang diprediksi dengan yang

diperoleh 
Hasil Analisis Data

Tabel 1 Uji Multikolinieritas

\begin{tabular}{crrrrrr} 
& RETURN & \multicolumn{1}{c}{ CR } & \multicolumn{1}{c}{ DER } & \multicolumn{1}{c}{ TATO } & \multicolumn{1}{c}{ ROE } & \multicolumn{1}{c}{ EPS } \\
\hline \hline RETURN & 1.000000 & -0.088454 & 0.462568 & 0.013281 & 0.586330 & 0.223526 \\
CR & -0.088454 & 1.000000 & -0.713020 & -0.183339 & -0.113177 & 0.079589 \\
DER & 0.462568 & -0.713020 & 1.000000 & 0.152810 & 0.386539 & 0.014542 \\
TATO & 0.013281 & -0.183339 & 0.152810 & 1.000000 & -0.045235 & -0.210862 \\
ROE & 0.586330 & -0.113177 & 0.386539 & -0.045235 & 1.000000 & 0.585578 \\
EPS & 0.223526 & 0.079589 & 0.014542 & -0.210862 & 0.585578 & 1.000000
\end{tabular}

Sumber: data diolah

Dapat dikatakan bahwa multikolinieritas tidak terjadi, karena korelasi setiap variabel di bawah 0,8. Maka dari itu, data lulus uji asumsi klasik, dan digunakan Random Effect Model.

Persamaan regresi yang terbentuk pada model Random Effect Model ini adalah sebagai berikut.

$$
R n=-0,8724+0,1254 C R+0,6329 D E R-0,001 T A T O+1,0097 R O E-0,001 E P S
$$

Keterangan:

$\begin{array}{ll}\mathrm{Rn} & =\text { Return Saham } \\ \mathrm{CR} & =\text { Current Ratio } \\ \mathrm{DER} & =\text { Debt Equity Ratio }\end{array}$

Current Ratio berpengaruh secara positif dan signifikan terhadap return saham perusahaan sektor Food and Beverage tahun 2013-2018. Dalam penelitian ini, diketahui bahwa nilai probabilitas sebesar 0,0126 yang berarti memiliki pengaruh yang signifikan karena nilainya berada di bawah 0,05 .

Debt Equity Ratio berpengaruh secara negatif dan signifikan terhadap return saham perusahaan sektor Food and Beverage tahun 2013-2018. Dalam penelitian ini, diketahui bahwa nilai probabilitas sebesar 0,0008 yang berarti memiliki pengaruh yang signifikan karena nilainya berada di bawah 0,05 .

Total Asset Turnover berpengaruh secara negatif dan signifikan terhadap return saham perusahaan sektor Food and Beverage tahun 2013-2018. Dalam penelitian ini, diketahui bahwa nilai probabilitas sebesar 0,9916 yang berarti tidak memiliki pengaruh yang signifikan karena nilainya berada di atas 0,05.

Return On Equity berpengaruh secara positif dan signifikan terhadap return saham perusahaan sektor Food and Beverage tahun 2013-2018. Dalam penelitian ini, diketahui bahwa nilai probabilitas sebesar 0,0007 yang berarti memiliki pengaruh yang signifikan karena nilainya berada di bawah 0,05 . 
Earnings per Share berpengaruh secara positif dan signifikan terhadap return saham perusahaan sektor Food and Beverage tahun 2013-2018. Dalam penelitian ini, diketahui bahwa nilai probabilitas sebesar 0,464 yang berarti tidak memiliki pengaruh yang signifikan karena nilainya berada di atas 0,05 .

\section{DISKUSI}

Current Ratio (CR) dikatakan sebagai rasio likuiditas dan menunjukan tingkat kemampuan perusahaan untuk membayar kewajiban jangka pendek dan membiayai kegiatan operasionalnya, jika perusahaan dapat membiayai kegiatan operasinya dengan baik maka investor akan lebih tertarik kepada perusahaan tersebut. Hasil dari penelitian ini sesuai dengan penelitian oleh W dan Sujana (2014) yang menyatakan Current Ratio (CR) berpengaruh positif dan signifikan terhadap return saham perusahaan Food and Beverage.

Debt Equity Ratio berpengaruh positif dan signifikan terhadap return saham sesuai dengan penelitian Purwitajati dan Putra (2016). Hal ini sesuai dengan teori saham high risk-high return. Tingkat $D E R$ yang semakin tinggi memang belum tentu membuat perusahaan semakin merugi, tergantung besar biaya modal pendanaan barunya.

Total Asset Turnover tidak berpengaruh signifikan terhadap return saham sesuai dengan penelitian oleh Ikhsani (2018). Total Asset Turnover tetap memiliki pengaruh negatif terhadap return saham walaupun tidak signifikan.

Return On Equity (ROE) berpengaruh positif dan signifikan terhadap return Saham, hal ini didukung oleh penelitian dari Setiyawan dan Pardiman (2014). Return On Equity mengukur besarnya jumlah pengembalian dibanding dengan modal yang dimiliki perusahaan. Semakin besar rasio ini, semakin baik kinerja perusahaan dalam menghasilkan return sebesar rasio ini dibanding dengan jumlah modal yang dimiliki.

Earnings per Share tetap ada pengaruh negatif karena koefisien negatif, namun tidak signifikan. Sesuai dengan penelitian oleh Rahmawati (2017) yang menyatakan bahwa Earnings per Share tidak memiliki pengaruh signifikan terhadap return saham. Hal ini berarti tingkat return saham lebih banyak dipengaruhi oleh faktor lainnya selain EPS.

\section{DAFTAR PUSTAKA}

Al - Tamimi, H. (2007). Factors affecting stock prices in the UAE financial markets. Singapore Economic Review Conference. https://editorialexpress.com/conference/ SERC2007

Chen, James. (2019). Earnings Per Share - EPS Definition. Investopedia. Dikutip dari https://www.investopedia.com/terms/e/eps.asp. 17 Agustus 2019.

Gitman, Lawrence J., Chad J Zutter. (2012). Principles of Managerial Finance: Thirteenth Edition. Essex: Pearson Education Limited.

Hadi, Sutrisno. (2000). Metodologi Research. Yogyakarta : Andi Yogyakarta.

Hartono, Jogiyanto. (2017). Teori Portofolio dan Analisis Investasi. Yogyakarta: BPFEYogyakarta.

Hidayat, Anwar. (2017). Penjelasan Metode Analisis Regresi Data Panel. Statistikian. Dikutip dari https://www.statistikian.com/2014/11/regresi-data-panel.html/amp . 28

Oktober 2019. 
Ikhsani, Mutiara. (2018). Pengaruh Roa, Der, Cr, Pbv Dan Tato Terhadap Return Saham (Studi Empiris Pada Perusahaan Real Estate And Property Yang Terdaftar Di Bursa Efek Indonesia Periode 2015-2018). Yogyakarta: Eprints Mercubuana Yogya

Jatmiko, Bambang Priyo. (2019). Mengenal Instrumen Risk Free Rate di Indonesia. Kompas.com. Dikutip dari https://money.kompas.com/read/2019/08/07/133000226/mengenal-instrumen-riskfree-rate-di-indonesia?page $=$ all. 23 Oktober 2019

Kasmir, (2013). Analisis Laporan Keuangan. Cetakan Keenam. Jakarta: Raja Grafindo Persada

Kenton, Will. (2019). Current Ratio. Investopedia. Dikutip dari https://www.investopedia.com/terms/c/currentratio.asp. 17 Agustus 2019.

Kenton, Will., Adam Hayes. (2019). Debt-To-Equity Ratio - D/E. Investopedia. Dikutip dari https://www.investopedia.com/terms/d/debtequityratio.asp. 17 Agustus 2019.

McLaney, E. , \& P Atrill. (2005). Accounting: An Introduction. Harlow: FT Prentice Hall.

Munawir, S. (2008). Analisis Informasi Keuangan, Cetakan Kedua. Yogyakarta: Liberty Yogyakarta.

Munawir. (2007). Analisis Laporan Keuangan. Liberty: Yogyakarta. (2010). Analisis Laporan Keuangan. Liberty: Yogyakarta.

Munggaran, A., Mukaram, \& Sarah, I. S. (2017). Pengaruh Earning Per Share (EPS) Terhadap Harga Saham. Jurnal Riset Bisnis \& Investasi, 3 (2), 3.

Permatasari, Sheila Silvia \& Mukaram, Mukaram. (2019). Pengaruh Rasio Keuangan Terhadap Harga Saham. Jurnal Riset Bisnis dan Investasi. 4. 47.

Purwitajati, Endah., dan I Made Pande Dwiana Putra. (2016). Pengaruh Debt To Equity Ratio pada Return Saham Dengan Ukuran Perusahaan Sebagai Pemoderasi. E-Jurnal Akuntansi Universitas Udayana. 15.2.

Saeidi, P., \& Khandoozi, B. (2011). The investigation of relation between market ratios and market price per share of accepted companies in tehran stock exchange. Global Business and Management Research, 3(2), 136-140.

Sarkar, Ankita. (2018). What Is Return On Equity Ratio (RoE)?. StockManiacs. Dikutip dari https://www.stockmaniacs.net/return-on-equity-ratio-roe/. 17 Agustus 2019.

Setiyawan, Indra., Padiman. (2014). Pengaruh Current Ratio, Inventory Turnover, Time Interest Earned dan Return On Equity Terhadap Harga Saham Pada Perusahaan Manufaktur Sektor Barang Konsumsi Yang Terdaftar Di BEI Periode 2009-2012. Jurnal Nominal. 3(2), 117-133.

Shaikh, A. S., Kashif, M., \& Shaikh, S. (2017). Measuring Stock Market Predictability With Implications Of Financial Ratios: An Empirical Investigation Of Pakistan Stock Market. Journal of Business Strategies, 11(1), 41-62,171-172.

Sitanggang, J. (2013). Manajemen Keuangan Perusahaan Lanjutan. 1st ed. Jakarta: Mitra Wacana Media.

Smart, Scott., Lawrence Gitman, Michael Joehnk. (2014). Fundamentals of Investing: Twelfth Edition. Essex: Pearson Education Limited.

Sucipto. (2003). Penilaian Kinerja Keuangan. FE Universitas Sumatera Utara.

Syaiful, Dian. (2016). Determinasi Rasio Keuangan Terhadap Return Saham. Jurnal Equity. 19. 1

Tandelilin, Eduardus. (2010). Portofolio dan Investasi: Teori dan Aplikasi: Edisi Pertama. Yogyakarta: Kanisius. 
W, Ni Nym Ayu Yuliantari dan Ketut Sujana. (2014). Pengaruh Financial Ratio, Firm Size, dan Cash Flow Operating terhadap Return Saham Food nad Beverage. Bali: EJurnal Akuntansi Universitas Udayana 8.1 (2014): 59-69

Widayanti, Rita., Fredella Colline. (2017). Pengaruh Rasio Keuangan terhadap Harga Saham Perusahaan LQ 45 Periode 2011-2015. Jakarta: Bina Ekonomi. 21(1), 36. 